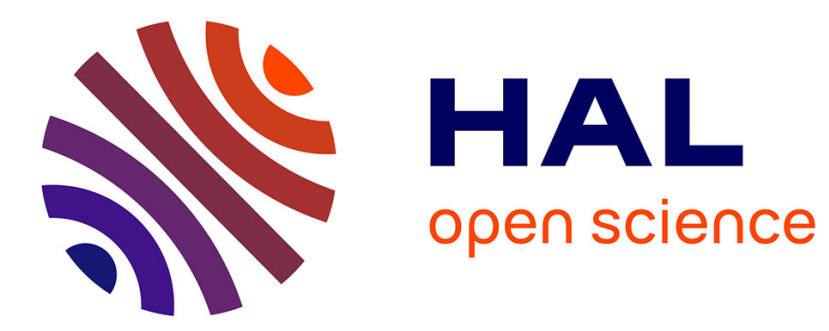

\title{
A novel mutation in the OFD1 (Cxorf5) gene may contribute to oral phenotype in OFD1 patients
}

Pedro Diz Dios, Vanesa Álvarez-Iglesias, Javier F. Feijoo, Jacobo Limeres, Juan Seoane, Inmaculada Tomas Carmona, Ángel Carracedo

\section{To cite this version:}

Pedro Diz Dios, Vanesa Álvarez-Iglesias, Javier F. Feijoo, Jacobo Limeres, Juan Seoane, et al.. A novel mutation in the OFD1 (Cxorf5) gene may contribute to oral phenotype in OFD1 patients. Oral Diseases, 2011, 17 (6), pp.610. 10.1111/j.1601-0825.2011.01823.x . hal-00657173

\section{HAL Id: hal-00657173 https://hal.science/hal-00657173}

Submitted on 6 Jan 2012

HAL is a multi-disciplinary open access archive for the deposit and dissemination of scientific research documents, whether they are published or not. The documents may come from teaching and research institutions in France or abroad, or from public or private research centers.
L'archive ouverte pluridisciplinaire HAL, est destinée au dépôt et à la diffusion de documents scientifiques de niveau recherche, publiés ou non, émanant des établissements d'enseignement et de recherche français ou étrangers, des laboratoires publics ou privés. 
A novel mutation in the OFD1 (Cxorf5) gene may contribute to oral phenotype in OFD1 patients

\begin{tabular}{|r|l|}
\hline Journal: & Oral Diseases \\
\hline Manuscript ID: & ODI-04-11-OM-2056.R1 \\
\hline Manuscript Type: & Original Manuscript \\
\hline Keywords: & Diagnostics, Genetics \\
\hline & \\
\end{tabular}

SCHOLARONE ${ }^{\text {M }}$

Manuscripts 
Title: A novel mutation in the OFD1 (Cxorf5) gene may contribute to oral phenotype in patients with oral-facial-digital syndrome type 1

Running title: OFD1 gene mutations and oral phenotype

Key words: oral-facial-digital syndrome, cleft palate, aberrant frenula, lobulated tongue, molecular screening, mutation

\section{Authors:}

Diz, $P^{1}$

Álvarez-Iglesias, $\mathrm{V}^{2}$

Feijoo, JF ${ }^{1}$

Limeres, $\mathrm{J}^{1}$

Seoane, $J^{3}$

Tomás, $I^{1}$

Carracedo, $\mathrm{A}^{2}$

\section{Affiliations:}

${ }^{1}$ Special Needs Unit. School of Medicine and Dentistry. Santiago de Compostela University (Spain).

${ }^{2}$ Grupo de Medicina Xenómica-Institute of Legal Medicine-CIBERER-Universidade de Santiago de Compostela (Spain).

${ }^{3}$ Stomatology Department. School of Medicine and Dentistry. Santiago de Compostela University (Spain).

\section{Correspondence:}

Pedro Diz Dios (pedro.diz@usc.es)

Special Needs Unit. School of Medicine and Dentistry

c/ Entrerríos sn

15782 Santiago de Compostela (A Coruña)

Spain

Date of submission: April $27^{\text {th }}, 2011$ 


\section{ABSTRACT \\ Background}

Oral-facial-digital syndrome (OFDS) type 1 (OFD1) is an X-linked dominant condition associated with embryonic male lethality. It almost always affects the oral cavity, face, and digits. It is considered to be a ciliopathy caused by mutations in the OFD1 gene. A variety of mutations have been described, and a genotype-phenotype correlation has been suggested.

\section{Objective and Methods}

The proband was an 8-year-old Spanish girl with suspected OFD1. We extended the pedigree to three proband's generations, performing a thorough physical examination and screening for OFD1 mutations in 9 individuals.

\section{Results}

The proband, her mother and her sister showed oral findings consistent with OFD1. Ultrasound evaluation revealed the existence of renal cysts only in the proband's mother. The rest of the family (all male) had no relevant morphological abnormalities. A single-base deletion in exon 16 of OFD1 (c.2183delG) leading to a frameshift was detected in the proband, her mother, and her sister.

\section{Conclusion}

Since all three women had a similar oral phenotype, this new mutation might be involved in the development of the OFD1 oral manifestations. In cases of OFDS, physical examination (including the oral cavity and renal function), and genetic screening of the probands and their relatives are mandatory. 


\section{INTRODUCTION}

The oral-facial-digital syndrome (OFDS) was first described by Mohr in 1941 (Mohr, 1941), when he reported a family with highly arched palate, lobate tongue with papilliform outgrowths, broad nasal root, hypertelorism, and digital anomalies. It is possible, however, that this condition was described previously, and in fact a report of apparent Mohr syndrome can be found 100 years earlier in the literature as 'Monstrorum humanum hexadactylum' (Beckwith, 1841). OFDS shows a striking phenotypic heterogeneity. To date, 13 types of OFDS have been described based on clinical manifestations and inheritance patterns (Gurrieri et al., 2007).

OFDS type 1 (OFD1; OFDI; OMIM 311200) was described by Papillon-Leage and Psaume in 1954 (Papillon-Leage and Psaume, 1954). It is inherited as an X-linked dominant trait with embryonic male lethality (Wettke-Schäfer and Kantner, 1983). Type 1 accounts for the majority of OFDS cases, and its estimated frequency is approximately 1 case per 50,000-250,000 live births (Wahrman et al., 1966). It has been suggested that OFDS reflects the pleiotropic effects of a morphogenetic impairment that almost invariably affects the oral cavity, face, and digits (Gurrieri et al., 2007). The main oral manifestations in OFD1 include pseudo-cleft of the upper lip, cleft palate, hyperplastic frenula, aberrant frenula, lobulated or cleft tongue (bifid or trifid), lingual hamartomas, ankyloglossia, hypodontia, supernumerary teeth, and hypoplastic mandible (Lauterstein and Pruzansky, 1969; Melnick and Shields, 1975; ThauvinRobinet et al., 2006; Hennekam et al., 2010a). The facies is remarkably characteristic, with frontal bossing, hypertelorism, dystopia cantorum, telecanthus, hypoplasia of alar cartilages, broad nasal root, low-set ears, flattened midfacial region, and microretrognathia (Macca and Franco 2009; Hennekam et al., 2010). Digital findings include brachydactyly, syndactyly, clinodactyly, polydactyly, and irregular bone mineralization (Al-Qattan and Hassanain, 1997; Hennekam et al., 2010). Bilateral polycystic kidney disease is common in OFD1, though most cases are detected in adulthood (Scolari et al., 1997). Central nervous system malformations include agenesis of the corpus callosum, arachnoid cysts, cerebellar abnormalities, hydrocephalus, and porencephaly. As many as $50 \%$ of cases have mild intellectual disability (Holub et al., 2005; Gurrieri et al., 2007).

OFD1 is caused by mutations in the Cxorf5 transcript, later named OFD1 (MIM\# 300170) (Ferrante et al., 2001), which comprises 23 exons encoding a 1011 amino acid protein. The gene encodes a centrosomal protein found in the primary cilia (Romio et al., 2003), and consequently OFD1 has been considered a ciliopathy (Badano et al., 2006). It is widely expressed in metanephros, brain, tongue, and limb (Romio et al., 2003), which could explain the clinical expression of the syndrome. A variety of 
mutations have been described, and some genotype-phenotype correlations have been suggested (Thauvin-Robinet et al., 2006; Prattichizzo et al., 2008; Macca and Franco, 2009).

Diagnosis in a proband raises the level of suspicion for the proband's relatives. The objective of this study was to perform a thorough physical examination and screening for OFD1 mutations in a three-generation Spanish family with oral-facial-digital syndrome type 1, who had heterogeneous phenotypic findings.

\section{MATERIALS \& METHODS Pedigree Construction}

The proband was an 8-year-old girl who was referred by her pediatrician to the Special Needs Dentistry Unit at the University of Santiago de Compostela, Spain, with a diagnosis of multiple caries and abnormal dental eruption. She had a history of cleft palate, lobulated tongue, and syndactyly that had all been surgically corrected, along with agenesis of the corpus callosum and mild mental retardation. Physical examination also revealed hypertelorism, broad nasal root, sequelae arising from surgical closure of the cleft palate and bifid tongue, numerous thick fibrous bands in the lower mucobuccal fold (aberrant frenula), supernumerary maxillary deciduous canines, and absence of lower lateral incisors (Fig. 1). As OFD1 was suspected, we extended the pedigree to three generations, including 9 individuals (Fig. 2): 3 affected, 4 unaffected, and 2 deceased. All participants or their legal guardians (cases II6 and III1) provided informed consent to inclusion in the study, which was approved by the Ethics Committee of the University of Santiago de Compostela.

\section{Mutation Analysis}

Genomic DNA was extracted from buccal epithelial cells using the QIAamp DNA Mini Kit (Qiagen, Hilden, Germany) according to the manufacturer's protocol. The 23 exons of the OFD1 gene were amplified as described previously (Ferrante et al., 2001). PCR products were separated on polyacrylamide gels (T-9\%, C-5\%). After confirming the success of the amplification, the PCR product was purified with a Multiscreen PCR $_{\mu} 96$ Filter Plate (Millipore Corporation, Billerica, USA). Sequencing reactions were carried out on both strands of the PCR product using the ABI Prism BigDye Terminator v3.1 Cycle Sequencing Kit (Applied Biosystems, Foster City, USA) and the products were purified with the Montage®SEQ96 Sequencing Reaction Cleanup Kit (Millipore). Electrophoresis was performed on an ABI PRISM 3730xI ${ }^{\mathrm{TM}}$ Genetic Analyzer (AB). SeqScape v.2.5 (AB) software was set up to automatically detect the presence of mutations by comparison with a reference sequence (GeneBank NM_003611), and in 
addition all electropherograms were visually inspected. Finally, sequence variant descriptions were analyzed with the Mutalyzer $2.0 \beta-4$ program (www.LOVD.nl/mutalyzer) (Wildeman et al., 2008), and the software was used to predict the affected protein from the variant coding region.

\section{RESULTS}

\section{Clinical Diagnosis}

The proband (II6) had morphological characteristics consistent with OFD1 (ThauvinRobinet et al., 2006; Gurrieri et al., 2007). Orofacial examination of the proband's mother (I2) revealed pseudocleft palate, bifid tongue, aberrant frenula, and absence of the lower lateral incisors (Fig. 1), as well as one nostril smaller than the other; she had a history of two spontaneous male miscarriages with severe malformations (II1 and II2) before conceiving the proband ( 21 and 17 years earlier). Examination of the proband's sister (II3) revealed a slight pseudocleft palate and bifid tongue, aberrant frenula, and absence of the lower lateral incisors (Fig. 1). Ultrasound evaluation of the kidneys in the three affected women (I2, II3 and II6) revealed the existence of small, bilateral renal cysts only in the proband's mother (I2). The rest of the family (all male) had no relevant morphological abnormalities.

\section{Mutation Analysis}

A single base deletion (c.2183delG) in exon 16 of the OFD1 gene leading to a frameshift was identified. Mutation nomenclature numbering is based on the GenBank accession number_NM003611, with +1 as the A of the ATG initiation codon. The variant C.2183delG was present in the proband (II6), her mother (I2), and her sister (II3) (Fig.3). The predicted protein based on analysis with Mutalyzer $2.0 \beta-4$ software is p.(Gly728Alafs*89). As expected, the other members of the family did not carry the mutation.

\section{DISCUSSION}

\section{Clinical Findings}

The diagnosis of OFD1 is usually established at birth on the basis of characteristic oral, facial, and digital abnormalities (Toriello and Franco, 2010). In spite of the severe phenotypic findings observed in the proband, a suspected diagnosis OFDS had not been suggested until she was referred for oral evaluation at 8 years of age. In this case, the proband was the first affected family member. A pedigree was therefore constructed to rule out the possibility that other relatives might be undiagnosed due to incomplete penetrance or variable expressivity. 
It has been suggested that neither the oral nor the facial features of OFDS can be used to reliably distinguish $X$-linked from autosomal recessive variants (Siebert, 2008). Oral abnormalities including pseudocleft palate, bifid tongue, aberrant frenula, and absence of the lower lateral incisors were the most relevant findings in both the proband's sister and her mother. In a worldwide cohort of 120 individuals clinically diagnosed with OFD1, cleft palate/high arched palate was present in $23.5 \%$, tongue anomalies in $90.1 \%$, aberrant frenula in $65.4 \%$, and abnormal teeth in $42 \%$ (Prattichizzo et al., 2008). None of these abnormalities is specific to OFDS and accessory frenula, for instance, may be more suggestive of Pallister-Hall syndrome (Hennekam et al., 2010b).

The proband's mother had renal cystic disease. Renal impairment can be present at birth but usually develops later on, occurring in $63 \%$ of patients older than 18 years (Macca and Franco, 2009). Some reports describe renal disease as completely dominating the clinical course of the syndrome (Feather et al., 1997), indicating that morphological assessment and biochemical monitoring of renal function is necessary in OFD1 patients (Prattichizzo et al., 2008). The proband's mother also had a history of two male miscarriages. Male lethality usually occurs in the first or second trimester of pregnancy (Wettke-Schäfer and Kantner, 1983), and only a few exceptional male cases of OFD1 have been reported to date (Wahrman et al., 1966).

Efforts to classify OFDS into distinct types have met criticism based on reported individuals or family members with different phenotypic findings. As in the present case, affected family members may not exhibit defects of all three areas: oral region, face, and digits (Siebert, 2008). Clinical variability is often seen in affected females even within the same family (Toriello, 1988), possibly due to the different degrees of somatic mosaicism (Thauvin-Robinet et al., 2006). Although the findings described for OFD1 overlap with those observed in other OFDS types, it has been suggested that OFD1 can be distinguished because of its X-linked dominant inheritance with male lethality and the presence of cystic kidneys (Gurrieri et al., 2007). Consequently, the clinical findings in the proband, the pedigree analysis, and the molecular analysis of the OFD1 gene led to a diagnosis of OFD1.

\section{Mutation Analysis}

To date, 99 mutations have been described in the OFD1 gene, the majority of which have been identified in exons $3(14 \%), 8(14 \%), 9(10 \%), 12(6 \%), 13(10 \%)$, and 16 (7\%), which may represent mutational hotspots (Macca and Franco, 2009). Intriguinly, no mutations or polymorphisms were identified beyond exon 16 (Macca et al, 2008). The mutation in exon 16 identified in this study is the hundredth to be reported. This is a deletion mutation causing a frameshift. Previously, 8 frameshift mutations and 1 
splice site mutation have been described in exon 16 and intron 16 respectively (Macca and Franco, 2009). As with many of the other mutations that have been described, it is predicted to cause premature truncation of the protein that would probably lead to loss of function (Gurrieri et al., 2007; Prattichizzo et al., 2008).

In more than $20 \%$ of patients, bi-directional DNA sequencing of the exons and intronexon boundaries of the OFD1 gene remains negative, but in $23 \%$ of these cases a genomic deletion of the OFD1 transcript has been identified through a combination of quantitative multiplex PCR of short fluorescent fragments (QMPSF) and relative quantification by real-time PCR (qPCR) (Thauvin-Robinet et al., 2008). However, only $85 \%$ of cases are explained by identifiable deletions and mutations, while the remaining cases are not identified using currently available techniques (Macca and Franco, 2009). Recently, Thauvin-Robinet et al (Thauvin-Robinet et al., 2009), in an effort to identify new regions containing candidate genes that could be implicated in OFDS, performed high-resolution array-CGH in a series of OFDS patients, but without success. Furthermore, genomic deletions of the OFD1 transcript have been identified in cases in which direct sequencing of the exons was negative due to the presence of the wild-type allele (Morisawa et al., 2004; Thauvin-Robinet et al., 2009).

When analysing genotype-phenotype correlations, mental retardation was more frequently associated with mutations in exons 3, 8, 9, 13 and 16 (Thauvin-Robinet et al., 2006). Polycystic kidney disease appears to be correlated with splice mutations (Thauvin-Robinet et al., 2006), mainly located in exons 9 and 12 (Prattichizzo et al., 2008). High-arched/cleft palate was found most frequently with missense and splice site mutations (Prattichizzo et al., 2008). Cleft lip was more often associated with mutations in exon 3 (Prattichizzo et al., 2008). Tongue anomalies were more often detected in patients showing a mutation in exon 12, and tooth abnormalities more frequently associated with mutations in coiled-coil domains (Toriello and Franco, 2010). Extensive phenotypic variability has been detected even among female members of the same family, probably due to $X$ inactivation (Thauvin-Robinet et al., 2006; Macca and Franco, 2009). Another possible explanation for the inter- and intrafamilial variability observed in OFD1 patients could be ascribed to modifier genes (Prattichizzo et al., 2008). To our knowledge, in the literature no correlation has been found between OFD1 clinical features and frameshift compared with other mutations. Moreover, mutations located in exon 16 have not been related to any specific phenotype to date. In the present paper, the three women with OFD1 carried the c.2183delG variant and had a similar oral phenotype, suggesting that the deletion could be implicated in the development of the oral manifestations of the syndrome. 
Further molecular studies will be required before adequate genetic counselling can be offered to all family members of affected individuals. Nevertheless, it is of critical importance to offer a thorough physical examination and molecular screening of OFD1 to the probands and their relatives, along with monitoring of renal function.

\section{COMPETING INTERESTS}

The authors declare that they have no competing interests

\section{ACKNOWLEDGMENTS}

We thank the family members for their willing cooperation, and Susana Rubido for her technical assistance. 


\section{REFERENCES}

Al-Qattan MM, Hassanain JM (1997). Classification of limb anomalies in oral-facialdigital syndromes. J Hand Surg Br 22:250-252.

Badano JL, Mitsuma N, Beales PL, Katsanis N (2006). The ciliopathies: an emerging class of human genetic disorders. Annu Rev Genomics Hum Genet 7:125-48.

Beckwith JB (1841). 'Monstrorum humanum hexadactylum' (personal communication). In: Otto, Adolph Wilhelm. Monstrorum Sexentorum Descriptio Anatomica. Vratislaviae: F. Girt, Case 460.

Feather SA, Winyard PJ, Dodd S, Woolf AS (1997). Oral-facial-digital syndrome type 1 is another dominant polycystic kidney disease: clinical, radiological and histopathological features of a new kindred. Nephrol Dial Transplant 12:1354-1361.

Ferrante MI, Giorgio G, Feather SA, Bulfone A, Wright V, Ghiani M, et al. (2001). Identification of the gene for oral-facial-digital type I syndrome. Am J Hum Genet 68:569-576.

Gurrieri F, Franco B, Toriello H, Neri G (2007). Oral-facial-digital syndromes: Review and diagnostic guidelines. Am J Med Genet Part A 143A:3314-3323.

Hennekam RCM, Krantz ID, Allanson JE (2010a). Gorlin's Syndromes of the Head and Neck. New York: Oxford University Press, 923-936.

Hennekam RCM, Krantz ID, Allanson JE (2010b). Gorlin's Syndromes of the Head and Neck. New York: Oxford University Press, 1182-1185.

Holub M, Potocki L, Bodamer OA (2005). Central nervous system malformations in oral-facial-digital syndrome, type 1. Am J Med Genet Part A 136A:218.

Lauterstein AM, Pruzansky S (1969). Tooth anomalies in the oral-facial-digital syndrome. Teratology 2:137-145.

Macca M, Franco B (2009). The Molecular Basis of Oral-Facial-Digital Syndrome, Type1. Am J Med Genet C Semin Med Genet 151C:318-325.

Melnick M, Shields ED (1975). Orofaciodigital syndrome, type I: a phenotypic and genetic analysis. Oral Surg Oral Med Oral Pathol 40:599-610.

Mohr OL (1941). A hereditary subletal syndrome in man. Skr Norske Vidensk Akad, I Mat-Naturv 14:3.

Morisawa T, Yagi M, Surono A, Yokoyama N, Ohmori M, Terashi H, et al. (2004). Novel double-deletion mutations of the OFD1 gene creating multiple novel transcripts. Hum Genet 115:97-103.

Papillon-Leage E, Psaume J (1954). Hereditary abnormality of the buccal mucosa: abnormal bands and frenula. Revue Stomatol 55:209-227. 
Prattichizzo C, Macca M, Novelli V, Giorgio G, Barra A, Franco B, the Oral-FacialDigital Type I (OFDI) Collaborative Group (2008). Mutational spectrum of the oralfacial-digital type I syndrome: a study on a large collection of patients. Hum Mutat 29:1237-1246.

Romio L, Wright V, Price K, et al. (2003). OFD1, the gene mutated in oral-facial-digital syndrome type 1 , is expressed in the metanephros and in human embryonic renal mesenchymal cells. J Am Soc Nephrol 14:680-689.

Scolari F, Valzorio B, Carli O, Vizzardi V, Costantino E, Grazioli L, et al. (1997). Oralfacial-digital syndrome type I: an unusual cause of hereditary cystic kidney disease. Nephrol Dial Transplant 12:1247-1250.

Siebert JR (2008). The oral-facial-digital syndromes. Handb Clin Neurol 87:341-351.

Thauvin-Robinet C, Callier P, Franco B, Zuffardi O, Payet M, Aral B, et al. (2009). Search for genomic imbalances in a cohort of 20 patients with oral-facial-digital syndromes negative for mutations and large rearrangements in the OFD1 gene. Am J Med Genet A 149A:1846-1849.

Thauvin-Robinet C, Cossée M, Cormier-Daire V, Van Maldergem L, Toutain A, Alembik $Y$, et al. (2006). Clinical, molecular, and genotype-phenotype correlation studies from 25 cases of oral-facial-digital syndrome type 1: a French and Belgian collaborative study. J Med Genet 43:54-61.

Thauvin-Robinet C, Franco B, Saugier-Veber P, Aral B, Gigot N, Donzel A, et al. (2008). Genomic deletions of OFD1 account for $23 \%$ of oral-facial-digital type 1 syndrome after negative DNA sequencing. Hum Mutat 30:E320-329.

Toriello HV (1988). Heterogeneity and variability in the oral-facial-digital syndromes. Am J Med Genet Suppl. 4:149-159.

Toriello HV, Franco B (2010). Oral-Facial-Digital Syndrome Type I. In: Pagon RA, Bird TC, Dolan CR, Stephens K, editors. GeneReviews [Internet]. Seattle (WA): University of Washington, Seattle; 1993-2002 [updated 2010 Oct 14].

Wahrman J, Berant M, Jacobs J, Aviad I, Ben-Hur N (1966). The oral-facial-digital syndrome: a male-lethal condition in a boy with 47/xxy chromosomes. Pediatrics 37:812-821.

Wettke-Schäfer R, Kantner G (1983). X-linked dominant inherited diseases with lethality in hemizygous males. Hum Genet 64:1-23.

Wildeman M, van Ophuizen E, den Dunnen JT, Taschner PE (2008). Improving sequence variant descriptions in mutation databases and literature using the Mutalyzer sequence variation nomenclature checker. Hum Mutat 29:6-13. 


\section{FIGURE LEGENDS}

Figure 1. Oral findings.

\section{Figure caption}

12 (proband's mother, 43 years old) and II3 (proband's sister, 23 years old) had a pseudocleft palate, bifid tongue, aberrant frenula, and absence of the lower lateral incisors. II6 (proband, 8 years old) had a cleft palate and lobulated tongue that had been surgically corrected, along with aberrant frenula and absence of the lower lateral incisors.

Figure 2. Family pedigree

\section{Figure caption}

Unaffected male

Affected female

Deceased affected male

Peripheral blood samples were not available for deceased members and those marked with an asterisk.

The proband is indicated with an arrow.

Figure 3. Sequence analysis of PCR products of exon 16. a) Direct sequencing of the PCR product in an affected individual. b) Wild type. 


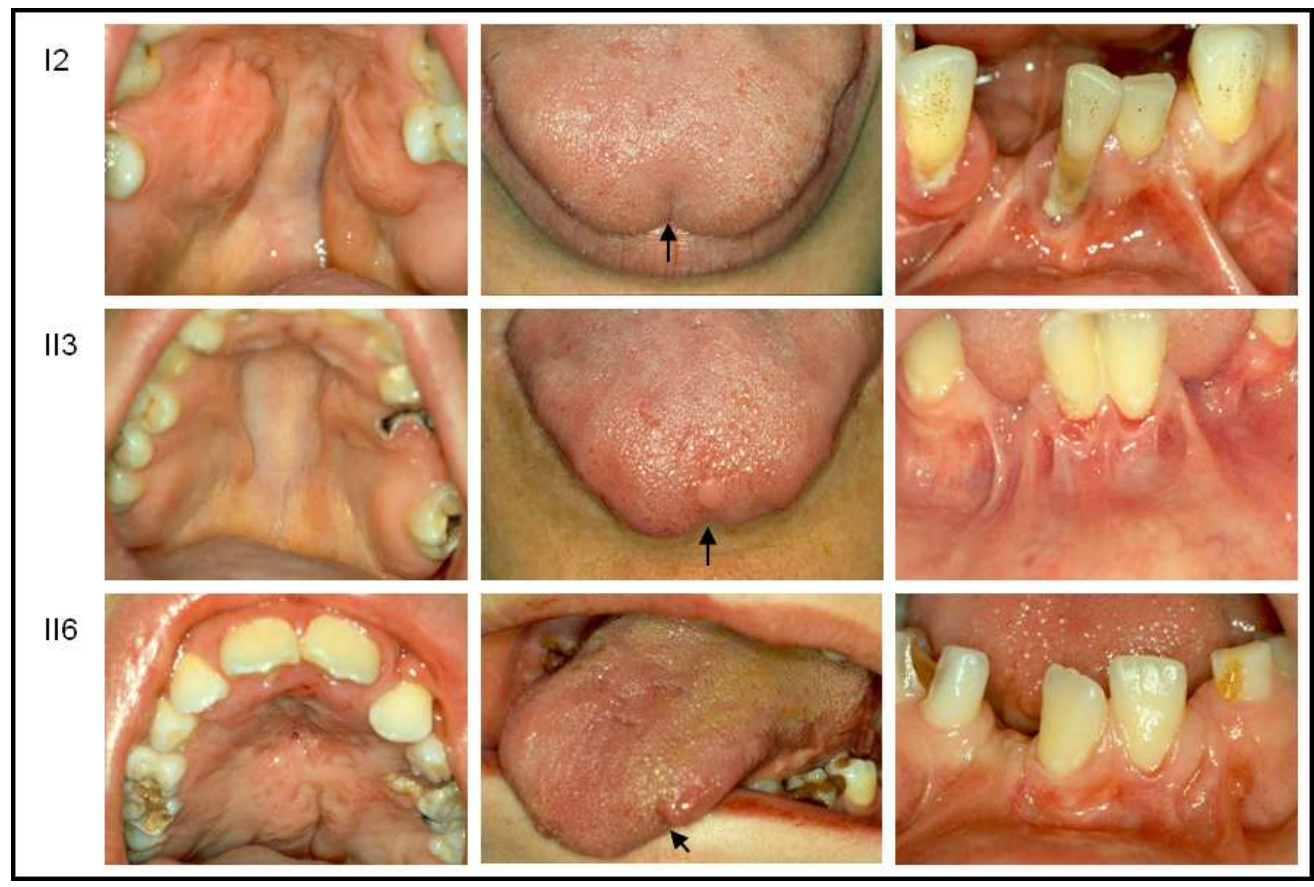

Figure title: Oral findings.

Figure caption

I2 (proband's mother, 43 years old) and II3 (proband's sister, 23 years old) had a pseudocleft palate, bifid tongue, aberrant frenula, and absence of the lower lateral incisors. II6 (proband, 8 years old) had a cleft palate and lobulated tongue that had been surgically corrected, along with aberrant frenula and absence of the lower lateral incisors.

$150 \times 101 \mathrm{~mm}(150 \times 150 \mathrm{DPI})$ 
Figure title: Family pedigree.

Figure caption

$\square$ Unaffected male Affected female

- Deceased affected male

Peripheral blood samples were not available for deceased members and those marked with an asterisk.

The proband is indicated with an arrow.

$$
137 \times 80 \mathrm{~mm}(150 \times 150 \text { DPI })
$$




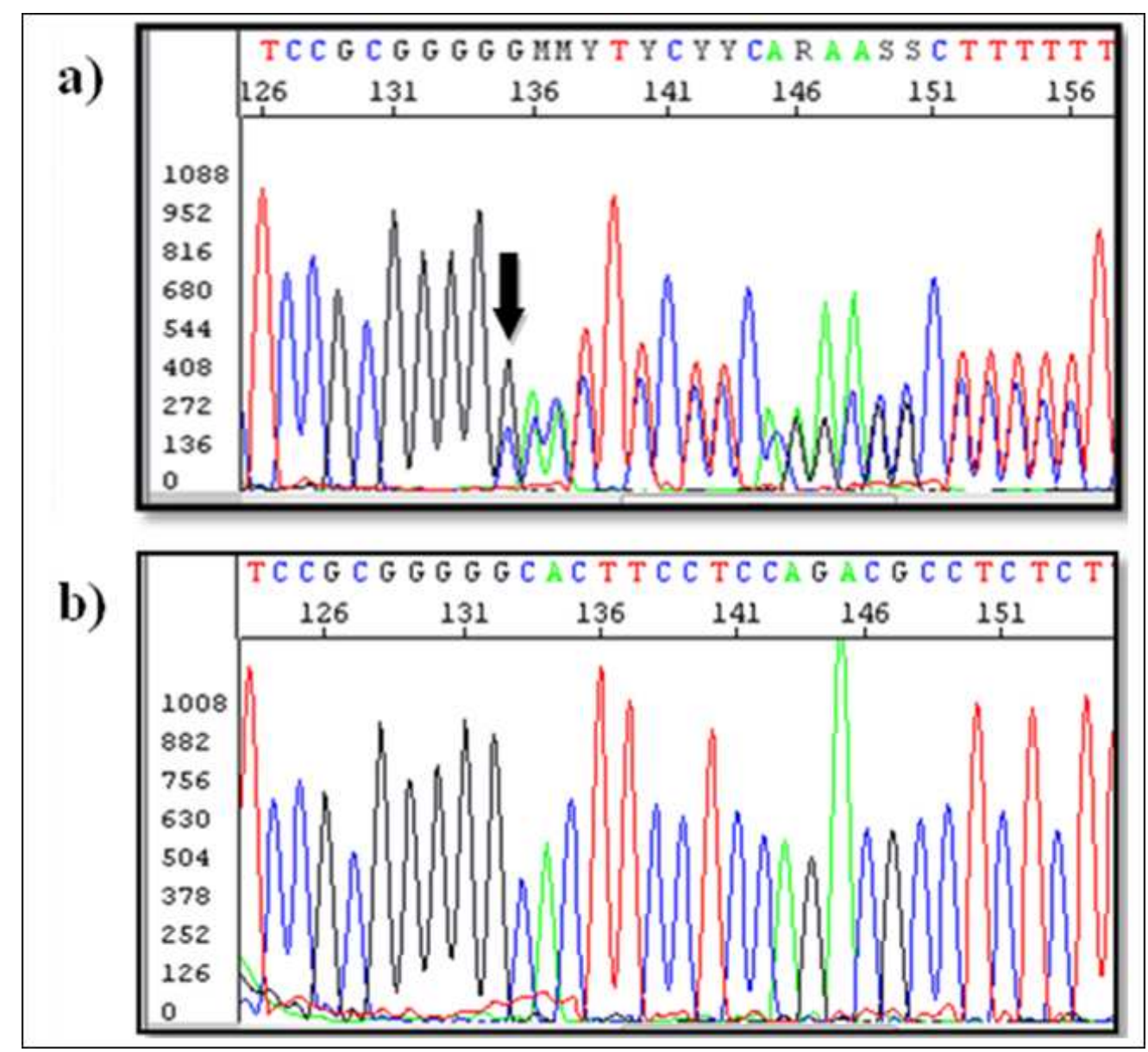

Figure title: Sequence analysis of PCR products of exon 16. a) Direct sequencing of the PCR product in an affected individual. b) Wild type. $109 \times 101 \mathrm{~mm}(150 \times 150 \mathrm{DPI})$ 